\title{
Cost-Effectiveness of the Adjuvant Recombinant Zoster Vaccine in Japanese Adults Aged 65 Years and Older
}

\author{
Makoto Shiragami · Akiko Mizukami - Toshihiko Kaise • \\ Desmond Curran - Desiree Van Oorschot - Benjamin Bracke • \\ Daisuke Watanabe
}

Received: February 22, 2019 / Published online: March 30, 2019

(c) The Author(s) 2019

\section{ABSTRACT}

Introduction: The incidence of herpes zoster (HZ) rises steeply after the age of 50 years and the number of $\mathrm{HZ}$ cases and complications such as postherpetic neuralgia ( $\mathrm{PHN})$ is predicted to increase because of the ageing population. The objective of this study was to estimate the costeffectiveness of recombinant zoster vaccine (RZV) compared with no vaccine for the Japanese population aged $\geq 65$ years.

Methods: A multi-cohort static Markov model with a cycle length of 1 year was used to follow a hypothetical cohort of 1 million people aged

Enhanced Digital Features To view enhanced digital features for this article go to https://doi.org/10.6084/ m9.figshare.7837922.

Electronic supplementary material The online version of this article (https://doi.org/10.1007/s13555019-0291-4) contains supplementary material, which is available to authorized users.

M. Shiragami

Faculty of Pharmaceutical Sciences, Teikyo Heisei University, Tokyo, Japan

A. Mizukami $(\bowtie) \cdot$ T. Kaise

Healthoutcomes Department, GSK, Tokyo, Japan

e-mail: akiko.mizukami@gsk.com

D. Curran · D. Van Oorschot · B. Bracke

Value Evidence Department, GSK, Wavre, Belgium

D. Watanabe

Department of Dermatology, Aichi Medical

University, Aichi, Japan $\geq 65$ years over their remaining lifetime. Vaccination at $\geq 65$ years was used in alignment with the influenza and pneumococcal vaccines recommended from 65 years. Japan-specific data inputs for the model were obtained from local data sources. Age-stratified vaccine efficacy and waning rates were based on published clinical trial data. In the base-case analysis, vaccine coverage was assumed to be $40 \%$ with a second dose compliance of $95 \%$. Costs and outcomes were discounted at $2 \%$ annually and the incremental cost-effectiveness ratio (ICER) was calculated from both a payer's and the societal perspective. Sensitivity analyses were carried out to explore the overall uncertainty in the model.

Results: Vaccination with RZV was projected to prevent 48,943 HZ cases and 12,136 PHN cases per million people aged $\geq 65$ years compared with no vaccination. The incremental costs and quality-adjusted life years (QALYs) gained were $¥ 9.99$ billion and 2314 QALYs from a payer’s perspective and ¥9.34 billion and 2314 QALYs from a societal perspective. The resulting ICERs were approximately $¥ 4,320,000$ and $¥ 4,040,000$ per QALY gained from a payer's and the societal perspective, respectively. The ICER remained below a willingness-to-pay threshold of $¥ 5,000,000$ for most sensitivity analyses carried out.

Conclusion: Vaccination against HZ with RZV would be cost-effective compared with no 
vaccination for the Japanese population aged $\geq 65$ years.

Trial Registration: GSK study identifier: HO16-17837.

Funding: GlaxoSmithKline Biologicals SA.

Keywords: Cost-effectiveness; Herpes zoster; Incremental cost-effectiveness ratio; Markov model; Postherpetic neuralgia; Qualityadjusted life years; Recombinant zoster vaccine; Vaccination

\section{INTRODUCTION}

Herpes zoster (HZ), also known as shingles, is a painful rash mainly affecting people with a weakened immune system due to ageing, malignant disease or immunosuppressive medication [1]. After primary infection with varicella zoster virus (VZV), which leads to varicella, also known as chickenpox, the virus remains dormant in the cranial nerve, dorsal root and autonomic ganglia. As cell-mediated immunity against VZV wanes because of advanced age or an immunocompromised state, the virus may replicate again leading to $\mathrm{HZ}$ [2]. As a result, a unilateral, vesicular rash develops in the affected dermatomes, which usually resolves after 4 weeks from symptom onset. However, several complications may arise, with the most common being postherpetic neuralgia (PHN), i.e., pain that persists long after the initial rash has resolved [3, 4]. The reported risk of developing PHN varies greatly because of differences in definition and study design [5]. Most commonly, PHN is defined as pain that persists for $\geq 90$ days after initial rash development; using this definition, between 5 and 30\% of patients with HZ experience PHN [5].

The majority of adults will have been infected with VZV during childhood or early adulthood as a result of varicella infection. In Japan, $>90 \%$ of people aged $\geq 20$ years test positive for anti-VZV antibodies and are at risk of developing HZ [6]. The lifetime risk is estimated at $30 \%$ and $\mathrm{HZ}$ incidence rises steeply after the age of 50 years [5]. In Japan, the reported HZ incidence was 10.9 per 1000 person-years in people aged $\geq 50$ years, and approximately $20 \%$ of patients proceeded to develop PHN [7].

In addition, epidemiological studies indicate an increase in the number of $\mathrm{HZ}$ cases, which exceeds that solely predicted by an ageing population $[5,8,9]$. In Japan, which has purportedly the highest proportion of elderly citizens worldwide, $\mathrm{HZ}$ and PHN pose a substantial disease burden in terms of loss of quality of life [10] and health care costs [11]. The economic burden is driven by medical costs relating to medications, outpatient visits and hospitalizations and was 2.7 times higher for $\mathrm{HZ}$ with PHN compared with HZ without any complications [11]. Current treatment options, including antivirals, analgesics and tricyclic antidepressants in case of PHN, provide only symptomatic relief and score low in terms of patient satisfaction with treatment efficacy [12]. Furthermore, based on a systematic review of randomized controlled trials, antivirals administered immediately at rash onset were no better than placebo in preventing PHN [13]. Thus, boosting cell-mediated immunity through vaccination is an attractive strategy to lower the incidence of $\mathrm{HZ}$ and PHN. To date, two vaccines have been developed for $\mathrm{HZ}$ prevention and have received approval in several countries. The first is zoster vaccine live (ZVL, Zostavax), a onedose vaccine using the same Oka strain as in the varicella vaccine. ZVL is however not available in Japan. Recently, another HZ-specific vaccine has been developed: the adjuvant recombinant zoster vaccine (RZV, Shingrix), a two-dose subunit vaccine that combines VZV glycoprotein $\mathrm{E}$, an important and highly abundant protein found on the VZV, with the proprietary adjuvant system $\mathrm{ASO1}_{\mathrm{B}}$ [14]. In Japan, RZV gained approval in March 2018 for HZ prevention in individuals aged $\geq 50$ years. In 2017, the Advisory Committee on Immunization Practices (ACIP) in the USA issued a preferential recommendation for the use of RZV for preventing shingles and related complications in people aged $\geq 50$ years [15]. Similar recommendations have been made by the National Advisory Committee on Immunization (NACI) in Canada [16]. In Germany, the Standing Committee on Vaccination (STIKO) has recently issued its recommendation for RZV vaccination in people 
with underlying diseases aged between 50 and 60 as well as a general recommendation for RZV vaccination in people aged $\geq 60$ years [17]. In Japan, the already existing varicella vaccine live (VVL) was approved by the Ministry of Health, Labour and Welfare (MHLW) in March 2016 for extended use in adults aged $\geq 50$ years for $\mathrm{HZ}$ prevention on the basis that its titre is comparable to ZVL [18].

The public health impact of introducing routine $\mathrm{HZ}$ vaccination with either VVL or RZV in Japan has recently been investigated [19]. Both vaccines significantly reduced the disease burden and resource utilization associated with $\mathrm{HZ}$ and PHN. RZV had a larger impact compared with VVL, avoiding approximately three to four times as many $\mathrm{HZ}$ and PHN cases and leading to a four- to five-fold higher reduction in the number of hospitalizations and outpatient visits [19]. The current vaccination schedule in Japan recommends several vaccines in adults aged $\geq 65$ years, including influenza and pneumococcal vaccine. Therefore, the objective of this study was to evaluate the cost-effectiveness of $\mathrm{RZV}$ in preventing $\mathrm{HZ}$ and its complications compared with no vaccination in Japanese adults aged 65 years and older to provide supportive evidence for policy making. In scenario analyses, the impact of age at vaccination on the incremental cost-effectiveness ratio (ICER) was evaluated by simulating cohorts aged 50, 60 and $\geq 70$ years.

\section{METHODS}

\section{Model Overview}

The ZOster ecoNomic Analysis (ZONA) model, a static multi-cohort Markov model, was developed to assess the cost-effectiveness of RZV in different cohorts $[20,21]$ and adapted for the Japanese context.

The model considers individuals aged $\geq 50$ years partitioned into five age groups (50-59, 60-64, 65-59, 70-79 and $\geq 80$ years) and follows all individuals within a cohort for their remaining lifetime from the year of vaccination. Individuals remain in their initial cohort and events are summed up in that cohort only. For the population of individuals aged $\geq 65$ years, the results for age groups of $65-69,70-79$ and $\geq 80$ years are combined. During each annual cycle, people may transition between different health states (no HZ, HZ, PHN, HZ-related complications other than PHN, recurrent HZ, HZ-related death and death due to natural cause) according to age-specific probabilities.

Vaccination with RZV is compared with no vaccination. Where possible, Japanese-specific data were selected for relevant input parameters.

\section{Methodological Assumptions}

The base case analysis for the ICER included a cohort of 1 million individuals aged $\geq 65$ years mimicking the Japanese age-distribution. Simulating a 1 million cohort allowed for comparison with other cost-effectiveness analyses carried out for different countries but using the same cohort size $[20,21]$. A payer's perspective including only direct medical costs was used for the base-case scenario based on the analysis of economic evaluation of vaccines and the guideline for economic evaluation of drugs/ medical devices in Japan [22, 23]. Costs and outcomes were evaluated over the remaining lifetime and discounted at $2 \%$ annually $[22,23]$. Results from a societal perspective were presented as part of scenario analyses.

\section{Model Inputs and Outputs}

\section{Demographic and Epidemiological Data}

Age-stratified population figures and all-cause mortality rates in 5-year age groups starting at age 50 years were retrieved from the Japanese Government Statistics provided by e-Stat, including estimates of the population and abridged life tables as of 2017 [24].

Epidemiological input variables used in the base case analysis were sourced from published literature, using Japanese literature where possible (Table 1). HZ incidence rates and the proportion of patients with HZ developing PHN were derived from a prospective cohort study in Japanese people aged $\geq 50$ years who were 
Table 1 Epidemiological input values and sources applied in base case, sensitivity and scenario analyses

\begin{tabular}{llll}
\hline Years of age & Base value & Lower bound for DSA & Upper bound for DSA
\end{tabular}

SE for PSA

Population size used to determine the proportions in the 1 million cohort

$\begin{array}{lll}50-59 & 15,749,000 & - \\ 60-64 & 7,805,000 & - \\ 65-69 & 9,921,000 & - \\ 70-79 & 14,486,000 & - \\ \geq 80 & 10,744,000 & - \\ \text { Source } & (24) & N A\end{array}$

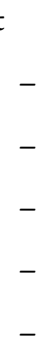

Annual incidence of initial and recurrent $\mathrm{HZ}$

$\begin{array}{lll}50-59 & 0.00920 & - \\ 60-69 & 0.00960 & 0.00768 \\ 70-79 & 0.01290 & 0.01032 \\ \geq 80 & 0.01260 & 0.01008 \\ \text { Source } & (7)^{\mathrm{a}} & -20 \%:(26,27)^{\mathrm{a}}\end{array}$

Initial and recurrent $\mathrm{HZ}$ cases with PHN (\%)

$\begin{array}{lll}50-59 & 14.60 & - \\ 60-69 & 14.60 & 7.30 \\ 70-79 & 20.20 & 10.10 \\ \geq 80 & 32.90 & 16.45 \\ \text { Source } & (7)^{\mathrm{b}} & -50 \%:(25)^{\mathrm{b}}\end{array}$

HZ-related complications other than PHN (\%)

$\begin{array}{llllr}50-69 & 5.1 & 1.9 & 8.3 & 0.0165 \\ \geq 70 & 10.6 & 6.7 & 14.5 & 0.0201 \\ \text { Source } & (11)^{\mathrm{c}} & (11)^{\mathrm{c}} & (11)^{\mathrm{c}} & \end{array}$

$\mathrm{HZ}$ mortality rate (\%)

$\begin{array}{ll}50-69 & 0.0000 \\ 70-74 & 0.0020 \\ 75-79 & 0.0092 \\ 80-84 & 0.0210 \\ 85-89 & 0.0467 \\ 90-94 & 0.1204 \\ 95-99 & 0.1960 \\ \geq 100 & 0.9476\end{array}$


Table 1 continued

\begin{tabular}{lllll}
\hline Years of age & Base value & Lower bound for DSA & Upper bound for DSA & SE for PSA \\
\hline Source & $(7,24)$ & $N A$ & $N A$ & - \\
\hline
\end{tabular}

$D S A$ deterministic sensitivity analysis, $H Z$ herpes zoster, $P H N$ postherpetic neuralgia, $P S A$ probabilistic sensitivity analysis, $R Z V$ recombinant zoster vaccine, $S E$ standard error

a Takao et al. reported an incidence rate of $\mathrm{HZ}$ in a community-based prospective cohort study [7]. The lower bound estimates were obtained from Toyama et al. [26, 27], and - 20\% was set based on the adjusted values by the updated HZ incidence ( 4.15 in 1997-2006 vs. 6.07 in 2017); assumed $+20 \%$ of base case for the upper bound. The recurrent HZ incidence was assumed to be the same as the initial $\mathrm{HZ}$ incidence

b The percentage of HZ with PHN was obtained from the same data source as the HZ incidence. The lower bound estimates were obtained from Sato et al. [25]; - 50\% was set based on the ratio of total PHN proportion in the two studies (9.2\%/19.7\%); assumed $+20 \%$ of the base case for the upper bound. The PHN proportion among HZ was assumed to be the same for both initial and recurrent cases

c Nakamura et al. reported overall incidence of non-pain complications including ocular, neurological and cutaneous ones in a prospective, observational cohort study of Japanese adults aged $\geq 60$ [11]. The incidence at ages 50-59 was assumed to be the same as that at ages 60-69. Ranges were set as $95 \%$ confidence intervals calculated from the published data in Nakamura et al. [11]

followed over a 3-year period [7]. This study was considered to provide the most reliable epidemiological information regarding HZ incidence because of its community-based approach (rather than institution-based) and prospective enrolment including adults aged $\geq 50$ years without applying additional selection criteria, thereby closely mimicking the realworld population. Data from other studies were used to inform upper and lower bounds used in sensitivity and scenario analyses [25-28]. HZ complication rates other than PHN were derived from a study by Nakamura et al. [11]. The incidences of recurrent $\mathrm{HZ}$ and PHN were assumed to be the same as those for the first occurrence based on several long-term studies showing that incidence of first-time and recurrent $\mathrm{HZ}$ was comparable [5, 29]. HZ-related mortality rates were retrieved from "Vital Statistics (2017)" provided by e-Stat [24].

\section{Vaccine Efficacy and Waning}

Recombinant zoster vaccine efficacy (VE) and decrease of VE over time (waning) were derived from data collected in two phase III clinical trials [30, 31] as described in detail elsewhere $[21,32]$ (Supplementary Material [S]; Table S1). The vaccination coverage was assumed to be the same as that for a pneumococcal polysaccharide vaccine for older adults in Japan [33], i.e., 40\%.
In the base case analysis, second dose compliance was set to $95 \%$, in line with clinical trial data and in the absence of data regarding reallife second dose compliance in Japanese older adults $[19,30,31]$. It should be noted that compliance rates $>95 \%$ for the second or third dose of paediatric vaccines have been reported in Japan [33]. Compliance rates may however be different in the adult population; therefore, sensitivity analyses were carried out where second dose compliance was varied from 70 to $100 \%$.

\section{Utilities}

Utilities for the base case, sensitivity and scenario analyses were obtained from the same prospective cohort study from which cost data were derived [10] (Table 2). Quality-adjusted life year (QALY) loss due to HZ (with and without PHN) was calculated using the reported utility values and the PHN duration [28] (Table S2).

\section{Costs}

The cost inputs applied in the base case, sensitivity and scenario analyses are summarized in Table 3. Direct medical costs per HZ case were based on the data from a prospective cohort study [11] and retrospective database study [34]. The costs reported by Nakamura et al. were adjusted by the hospitalization rate reported by 
Table 2 Utility input values and sources applied in base case, sensitivity and scenario analyses

\begin{tabular}{|c|c|c|c|c|}
\hline & Base value & Lower bound for DSA & Upper bound for DSA & Standard error for PSA \\
\hline \multicolumn{5}{|l|}{ Baseline utility } \\
\hline 50-59 YOA & 0.962 & - & - & - \\
\hline $60-69$ YOA & 0.975 & - & - & - \\
\hline 70-79 YOA & 0.942 & - & - & - \\
\hline$\geq 80 \mathrm{YOA}$ & 0.883 & - & - & - \\
\hline Source & $(10)^{\mathrm{a}}$ & $N A$ & $N A$ & \\
\hline \multicolumn{5}{|c|}{ QALY loss per HZ } \\
\hline \multicolumn{5}{|l|}{ Without PHN } \\
\hline 50-59 YOA & 0.014 & - & - & - \\
\hline 60-69 YOA & 0.015 & 0.0120 & 0.0180 & 0.0015 \\
\hline 70-79 YOA & 0.020 & 0.0160 & 0.0240 & 0.0020 \\
\hline$\geq 80 \mathrm{YOA}$ & 0.017 & 0.0136 & 0.0204 & 0.0017 \\
\hline \multicolumn{5}{|l|}{ With PHN } \\
\hline $50-59$ YOA & 0.118 & - & - & - \\
\hline $60-69$ YOA & 0.135 & 0.1080 & 0.1620 & 0.0138 \\
\hline 70-79 YOA & 0.154 & 0.1232 & 0.1848 & 0.0157 \\
\hline$\geq 80 \mathrm{YOA}$ & 0.179 & 0.1432 & 0.2148 & 0.0183 \\
\hline Source & (10); Table $S 2^{\mathrm{b}}$ & $-20 \%:$ Assumption $^{\mathrm{b}}$ & $+20 \%:$ Assumption ${ }^{\mathrm{b}}$ & \\
\hline \multicolumn{5}{|c|}{ QALY loss from adverse event } \\
\hline Local/general & 0.0001 & - & - & - \\
\hline Hospitalization & 0.0082 & - & - & - \\
\hline Source & $(43)^{c}$ & $N A$ & $N A$ & \\
\hline
\end{tabular}

DSA deterministic sensitivity analysis, $H Z$ herpes zoster, $N A$ not applicable, $P H N$ postherpetic neuralgia, $P S A$ probabilistic sensitivity analysis, $Q A L Y$ quality-adjusted life year, $Y O A$ years of age

${ }^{a}$ Assumed to be the same as the utility at day 90 after $\mathrm{HZ}$ onset for $\mathrm{HZ}$ patients without PHN obtained from a prospective cohort study reported by Mizukami et al. [10]

${ }^{\mathrm{b}}$ QALY loss was estimated by the same data source for baseline utility. QALY loss per HZ without PHN was calculated using the utilities between day 0 and day 90 for HZ patients without PHN; QALY loss per HZ with PHN was calculated using the utilities between day 0 and day 90 for HZ patients with PHN and PHN duration reported by Imafuku et al. [28], as illustrated in Table S2. Age 50-59 was assumed to be the same as age 60-64, assumed to be a range of $\pm 20 \%$ in the sensitivity analysis

c Applied QALY losses for local/general and hospitalization adverse events (AEs) to be consistent with Le and Rothberg [43]; it is implicitly assumed that persons requiring an outpatient or ER visit from AEs experienced the QALY loss related to a local/general reaction. The model calculates a weighted AE QALY loss per dose based on the incidence of the four AEs and the QALY losses per event. The weighted QALY loss per dose is varied by $+100 \%$ and $-50 \%$ in sensitivity analysis, so no ranges are used for the individual costs per $\mathrm{AE}$ 
Sato et al., resulting from the same prospective cohort study [25]. In addition, the cost for patients with PHN was converted into the annual cost by adding the treatment cost of PHN reported by Honda et al. [34]. An official price for RZV in Japan has not been disclosed or listed yet. Therefore, for the base case analysis and excluding consumption tax, an RZV hypothetical price of $¥ 12,000$ per dose was assumed with a range of $¥ 10,000$ - $¥ 15,000$ used in sensitivity analyses, which is broadly similar to the price assumed in the US and German cost-effectiveness publications $[20,21]$. The administration cost per dose was set to $¥ 3170$ based on a medical fee point scheme [35]. A consumption tax of $8 \%$ was added to all costs. Indirect costs due to $\mathrm{HZ}$ included the productivity loss for patients and their caregivers [11]. The productivity loss for patients was calculated based on the number of visits and admission days in HZ with and without PHN (Table S3) and standardized by an hourly wage and an employment rate obtained from "Basic survey of wage structure (2017)" and "Survey of labour force (2017)", respectively, by age groups $>50$ in Japan [24]. As there is no information on adverse event costs by vaccination, the costs by categories were assumed based on an expert opinion.

Health outcomes included the numbers of $\mathrm{HZ}$, PHN cases and HZ complications other than PHN avoided and number of deaths avoided from $\mathrm{HZ}$ over the entire time horizon. Costs included vaccinations costs, direct costs and indirect costs (for the societal perspective only). All costs were expressed in Japanese yen (¥) as of 2017.

The resulting ICERs were compared with a willingness-to-pay (WTP) threshold of $¥ 5,000,000$ per QALY gained, commonly used in Japan [36].

\section{Sensitivity and Scenario Analyses}

Deterministic one-way sensitivity analyses (DSAs) were performed by varying each of the model's input variables one at a time over the ranges presented in Tables 1,2 and 3 and in
Table S1. Ranges were chosen based on alternative values reported in the literature. Probabilistic sensitivity analyses (PSAs) were conducted to observe the variation in cost-effectiveness. In PSA, 5000 Monte Carlo simulations were carried out where input values were simultaneously sampled from probability distributions. Cost parameters were sampled across gamma or uniform distributions. A uniform distribution was used for second dose compliance, while a beta distribution was applied to all other parameters.

Threshold analyses were conducted on different parameters, i.e., initial efficacy of RZV (two doses), HZ incidence (initial and recurrent), vaccine price, waning of efficacy and QALY loss associated with HZ (with/without PHN). These parameters were varied by steps of $10 \%$ from -100 to $+100 \%$ to assess the impact on the ICER and the potential to reach the WTP threshold.

Scenario analyses were performed to explore the impact of age at vaccination on the ICER, including cohorts of adults aged 50, 60 and $\geq 70$.

\section{Compliance with Ethics Guidelines}

This article is based on previously conducted studies and does not contain any studies with human participants or animals performed by any of the authors.

\section{RESULTS}

\section{Base-Case Analysis}

Results for the base case analysis for a cohort of 1 million Japanese adults aged $\geq 65$ years are shown in Table 4 . The model estimated that RZV would prevent 48,983 HZ cases; 12,136 PHN cases and 5918 other complications compared with no vaccination over the remaining lifetimes of all individuals included in the model. This corresponds to a reduction of $23-24 \%$ in these outcomes leading to 2314 
Table 3 Cost input values and sources applied in base case, sensitivity and scenario analyses

\begin{tabular}{|c|c|c|c|c|}
\hline & Base value & $\begin{array}{l}\text { Lower bound } \\
\text { for DSA }\end{array}$ & $\begin{array}{l}\text { Upper bound } \\
\text { for DSA }\end{array}$ & $\begin{array}{l}\text { Standard error } \\
\text { for PSA }\end{array}$ \\
\hline \multicolumn{5}{|l|}{ Direct medical costs } \\
\hline \multicolumn{5}{|l|}{ Costs per $\mathrm{HZ}$ case } \\
\hline Without any complications & 38,471 & 35,575 & 41,367 & 1478 \\
\hline With PHN & 127,079 & 90,164 & 163,994 & 18,834 \\
\hline $\begin{array}{l}\text { With non PHN-related } \\
\text { complications }\end{array}$ & 72,789 & 37,482 & 108,096 & 18,014 \\
\hline Source & $(11,25,34)^{a}$ & $(11)^{\mathrm{a}}$ & $(11)^{\mathrm{a}}$ & \\
\hline \multicolumn{5}{|l|}{ Vaccination costs } \\
\hline RZV vaccine price per dose & 12,960 & $10,800^{\mathrm{b}}$ & $16,200^{\mathrm{b}}$ & - \\
\hline Source & Assumption ${ }^{c}$ & Assumption & Assumption & - \\
\hline Administration cost per dose & 3424 & $2568^{\mathrm{b}}$ & $4280^{\mathrm{b}}$ & - \\
\hline Source & Assumption ${ }^{\mathrm{d}}$ & - 25\%: Assumption & $+25 \%:$ Assumption & - \\
\hline \multicolumn{5}{|l|}{ Adverse event costs } \\
\hline Local/general & 0 & - & - & - \\
\hline Outpatient & 3957.5 & - & - & - \\
\hline ER & 8757.5 & - & - & - \\
\hline Hospitalization & 225,750 & - & - & - \\
\hline Source & Assumption $^{\mathrm{e}}$ & $N A$ & $N A$ & - \\
\hline \multicolumn{5}{|l|}{ Indirect costs } \\
\hline \multicolumn{5}{|l|}{ Costs per $\mathrm{HZ}$ case } \\
\hline \multicolumn{5}{|l|}{ Without PHN } \\
\hline 50-59 YOA & 17,747 & - & - & - \\
\hline 60-69 YOA & 15,128 & 11,346 & 18,910 & 1929 \\
\hline 70-79 YOA & 11,892 & 8919 & 14,865 & 1517 \\
\hline$\geq 80 \mathrm{YOA}$ & 15,115 & 11,336 & 18,894 & 1928 \\
\hline \multicolumn{5}{|l|}{ With PHN } \\
\hline 50-59 YOA & 57,662 & - & - & - \\
\hline 60-69 YOA & 32,733 & 24,550 & 40,916 & 4175 \\
\hline 70-79 YOA & 20,297 & 15,223 & 25,371 & 2589 \\
\hline$\geq 80 \mathrm{YOA}$ & 19,046 & 14,285 & 23,808 & 2429 \\
\hline
\end{tabular}


Table 3 continued

\begin{tabular}{lllll}
\hline & Base value & $\begin{array}{l}\text { Lower bound } \\
\text { for DSA }\end{array}$ & $\begin{array}{l}\text { Upper bound } \\
\text { for DSA }\end{array}$ & $\begin{array}{l}\text { Standard error } \\
\text { for PSA }\end{array}$ \\
\hline Source & $\begin{array}{c}\text { Derived from } \\
(11)^{\mathrm{f}}\end{array}$ & $-25 \%:$ Assumption & $+25 \%:$ Assumption \\
\hline
\end{tabular}

$D S A$ deterministic sensitivity analysis, $E R$ emergency room, $H Z$ herpes zoster, $P H N$ postherpetic neuralgia, $P S A$ probabilistic sensitivity analysis, $R Z V$ recombinant zoster vaccine, $Y O A$ years of age

${ }^{a}$ Nakamura et al. reported HZ-related costs for patients with HZ without any complications, with PHN, and with nonpain complications in a prospective cohort study [11]. The costs were adjusted by hospitalization rate reported by Sato et al. [25]. In addition, the cost for patients with PHN was converted into the annual cost by adding the PHN treatment cost for 3 months $(=95,809 / 6$ months $\times 3 / 6$ months $\times 50 \%)$ reported by Honda et al. [34]. Calculated a range from the standard error of the data reported by Nakamura et al. [11]

b This input was varied in one-way sensitivity analysis but was held at its base value(s) in probabilistic sensitivity analysis

c Assumed the price from the vaccination cost comparable to that used in the cost-effectiveness analysis in the US [21] and Germany [20]. Cost input was the price including $8 \%$ consumption tax

${ }^{d}$ Calculated based on medical fee point scheme in 2016; (2820 for initial visit +200 for biologics +150 for injection) $\times 1.08=¥ 3424$

e Assumed based on medical fee point scheme in 2016 according to expert opinion; no healthcare resource utilization for local/general; 2820 for initial visit +680 for prescription $+(15.9$ (Sodium Loxoprofen) + 14.6 (Rebamipide) $) \times 15 \mathrm{~T}=¥ 3957.5$ for Outpatient; 4800 for visit between 22:00 and 6:00 + AE cost for outpatient $=¥ 8757.5$ for ER. Assumed based on diagnosis procedure combination (DPC) point scheme in 2016; DPC code of 080100 (drug eruption) with admission for median duration, $25,940 \times 5+19,210 \times 5=¥ 225,750$ for Hospitalization. The model calculated a weighted adverse event $(\mathrm{AE})$ cost per dose based on the incidence of the four AEs and the costs per event. The weighted cost per dose was varied by $+100 \%$ and $-50 \%$ in sensitivity analysis, so no ranges were used for the individual costs per $\mathrm{AE}$

${ }^{\mathrm{f}}$ Indirect costs include productivity loss of patients and their caregivers. The productivity loss of patients was calculated based on the number of visits and admission days (Table S3). Assumed to be a range of $\pm 25 \%$ in sensitivity analysis

QALYs gained. The vaccination costs would total approximately $¥ 12.88$ billion, but the HZ cases prevented would save almost $¥ 2.89$ billion in direct costs and approximately $¥ 0.65$ billion in indirect costs. These outcomes equate to a cost of $¥ 4,316,457$ and $¥ 4,036,020$ per QALY gained from a payer's and societal perspective, respectively.

\section{Scenario Analysis}

In scenario analyses, the starting age at vaccination was varied from 50 to 70 years (Table 5). From a payer's perspective, the ICER for people aged $\geq 65$ years was the lowest among the four scenarios, though the differences were relatively small. Incremental QALYs increased with increasing age at vaccination, likely because of the higher incidence of $\mathrm{HZ}$ in the older age groups. At the same time, incremental costs increased with increasing age at vaccination resulting in ICERs that were similar across the four scenarios tested.

\section{Sensitivity Analysis}

One-way DSA for Japanese adults aged $\geq 65$ showed that the ICERs for the payer's and societal perspectives were most sensitive to the following inputs based on their defined ranges: annual waning of two-dose RZV efficacy for individuals aged $\geq 70$ years, proportion of patients with HZ developing PHN, HZ incidence, vaccine price and QALY loss per HZ case with PHN (Fig. 1). Changing the second dose compliance rate and initial efficacy of RZV had 
Table 4 Base case analysis results for 1 million Japanese adults aged $\geq 65$ years vaccinated with RZV vs. no vaccine

\begin{tabular}{|c|c|c|c|c|c|c|c|}
\hline \multicolumn{3}{|l|}{ Outcome } & \multicolumn{2}{|l|}{$\mathbf{R Z V}$} & No vaccine & \multicolumn{2}{|c|}{ RZV vs. no vaccine } \\
\hline \multicolumn{8}{|c|}{ Health outcomes } \\
\hline \multicolumn{3}{|l|}{$\mathrm{HZ}$ cases } & \multicolumn{2}{|l|}{152,103} & 201,086 & \multicolumn{2}{|c|}{$(48,983)$} \\
\hline \multicolumn{3}{|c|}{ PHN cases } & \multicolumn{2}{|l|}{41,420} & 53,556 & \multicolumn{2}{|c|}{$(12,136)$} \\
\hline \multicolumn{3}{|c|}{ Complication cases } & \multicolumn{2}{|l|}{15,672} & 20,590 & \multicolumn{2}{|l|}{$(4918)$} \\
\hline \multicolumn{3}{|c|}{ Death due to $\mathrm{HZ}$} & \multicolumn{2}{|l|}{35} & 42 & \multicolumn{2}{|l|}{ (7) } \\
\hline \multicolumn{8}{|c|}{ Costs (discounted) } \\
\hline \multicolumn{3}{|c|}{ Vaccination costs } & \multicolumn{2}{|c|}{$¥ 12,879,004,440$} & $¥ 0$ & \multicolumn{2}{|c|}{$¥ 12,879,004,440$} \\
\hline \multicolumn{3}{|c|}{ Direct costs due to $\mathrm{HZ}$} & \multicolumn{2}{|c|}{$¥ 8,588,964,332$} & $¥ 11,479,632,318$ & \multicolumn{2}{|c|}{$(¥ 2,890,667,986)$} \\
\hline \multicolumn{3}{|c|}{ Indirect costs due to $\mathrm{HZ}$} & \multicolumn{2}{|c|}{$¥ 1,897,343,257$} & $¥ 2,546,279,452$ & \multicolumn{2}{|c|}{$(¥ 648,936,196)$} \\
\hline QALYs (di & ounted) & & & & & & \\
\hline QALYs ga & ed & & $12,589,91$ & & $12,587,599$ & 2314 & \\
\hline Cost-effecti & ness & & & & & & \\
\hline ICER & & & & & & & \\
\hline Payer & & & - & & - & $¥ 4,316$ & 57/QALY \\
\hline Societal & & & - & & - & $¥ 4,036$ & 20/QALY \\
\hline $\begin{array}{l}H Z \text { herpes } \\
R Z V \text { recom }\end{array}$ & $\begin{array}{l}\text { er, } I C \\
\text { ant } \mathrm{z}\end{array}$ & $\begin{array}{l}\text { incremental cos } \\
\text { r vaccine, () ref }\end{array}$ & $\begin{array}{l}\text { ffectiveness } \mathrm{r} \\
\text { to savings }\end{array}$ & , PHN pos & rpetic neuralgia, & $Y$ quality-adju & ed life years, \\
\hline & Age & Payer's perspect & & & Societal persp & tive & \\
\hline & & $\begin{array}{l}\text { Incremental } \\
\text { cost }(¥)\end{array}$ & $\begin{array}{l}\text { Incremental } \\
\text { QALY }\end{array}$ & $\begin{array}{l}\text { ICER } \\
(¥ / Q A L Y)\end{array}$ & $\begin{array}{l}\text { Incremental } \\
\text { cost }(¥)\end{array}$ & $\begin{array}{l}\text { Incremental } \\
\text { QALY }\end{array}$ & $\begin{array}{l}\text { ICER } \\
\text { (¥/QALY) }\end{array}$ \\
\hline Base case & $\geq 65$ & $9,988,336,455$ & 2314 & $4,316,457$ & $9,339,400,259$ & 2314 & $4,036,020$ \\
\hline Scenario 1 & $\geq 50$ & $9,838,441,491$ & 2177 & $4,518,465$ & $9,024,002,320$ & 2177 & $4,144,421$ \\
\hline Scenario 2 & $\geq 60$ & $9,920,792,661$ & 2288 & $4,336,202$ & $9,230,655,772$ & 2288 & $4,034,556$ \\
\hline Scenario 3 & $\geq 70$ & $10,123,202,685$ & 2314 & $4,374,192$ & $9,529,813,540$ & 2314 & $4,117,791$ \\
\hline
\end{tabular}

ICER incremental cost-effectiveness ratio; $Q A L Y$ quality-adjusted life years

little impact on the ICER (data not shown). Threshold analyses showed that increasing either price or waning by approximately $20 \%$ would lead to an ICER close to the WTP threshold of $¥ 5,000,000 / \mathrm{QALY}$. Also, decreasing the efficacy of RZV (two doses), HZ incidence or
QALY loss per HZ case by approximately $10 \%$ would lead to ICERs close to the WTP threshold (Fig. 2). PSA demonstrated that $72.2 \%$ of simulations from a payer's perspective and $79.7 \%$ of simulations from a societal perspective resulted in an ICER below the commonly used WTP 

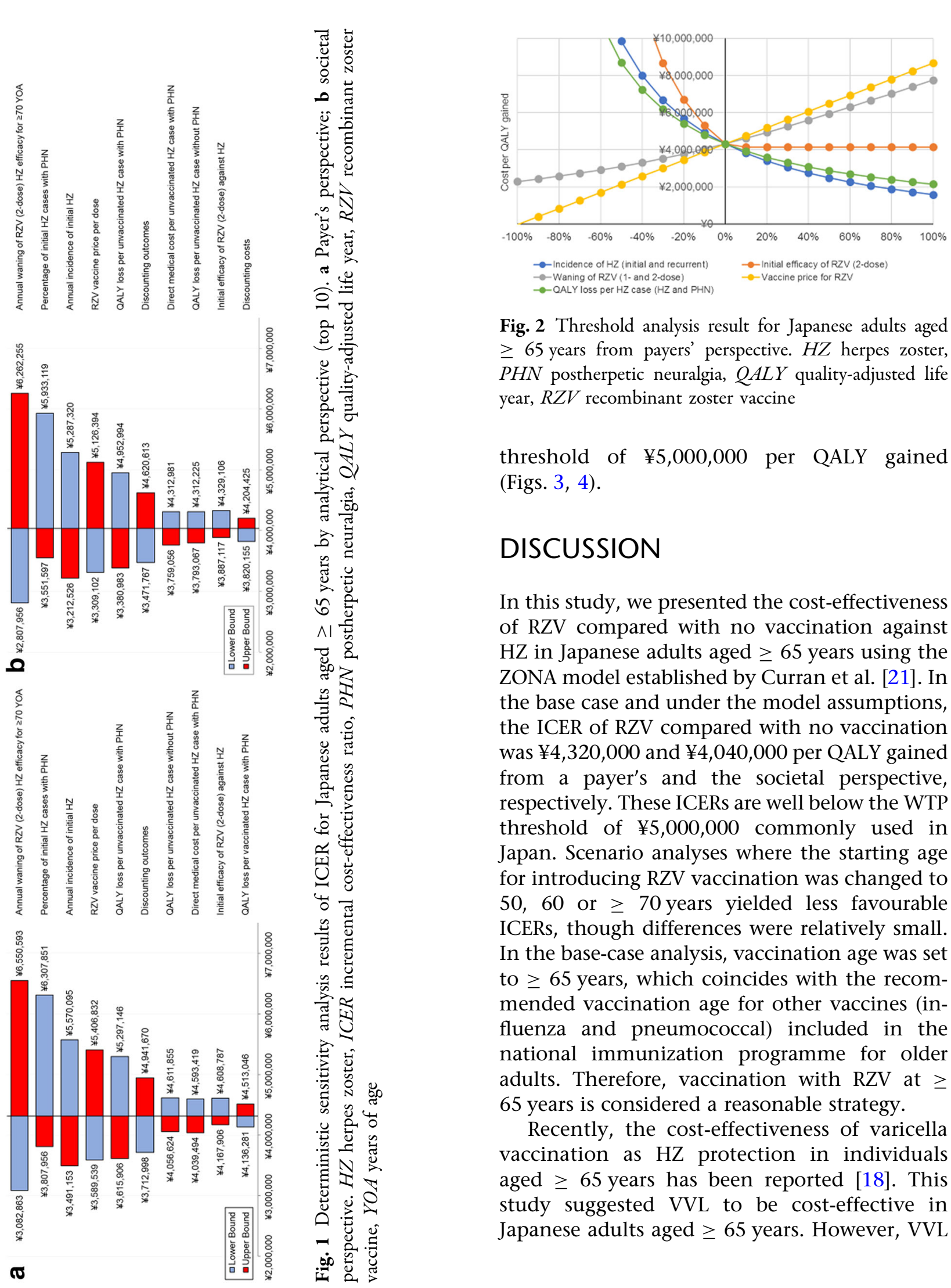

Fig. 2 Threshold analysis result for Japanese adults aged $\geq 65$ years from payers' perspective. $H Z$ herpes zoster, $P H N$ postherpetic neuralgia, QALY quality-adjusted life year, $R Z V$ recombinant zoster vaccine

threshold of $¥ 5,000,000$ per QALY gained (Figs. 3, 4).

\section{DISCUSSION}

In this study, we presented the cost-effectiveness of RZV compared with no vaccination against $\mathrm{HZ}$ in Japanese adults aged $\geq 65$ years using the ZONA model established by Curran et al. [21]. In the base case and under the model assumptions, the ICER of RZV compared with no vaccination was $¥ 4,320,000$ and $¥ 4,040,000$ per QALY gained from a payer's and the societal perspective, respectively. These ICERs are well below the WTP threshold of $¥ 5,000,000$ commonly used in Japan. Scenario analyses where the starting age for introducing RZV vaccination was changed to 50,60 or $\geq 70$ years yielded less favourable ICERs, though differences were relatively small. In the base-case analysis, vaccination age was set to $\geq 65$ years, which coincides with the recommended vaccination age for other vaccines (influenza and pneumococcal) included in the national immunization programme for older adults. Therefore, vaccination with RZV at $\geq$ 65 years is considered a reasonable strategy.

Recently, the cost-effectiveness of varicella vaccination as $\mathrm{HZ}$ protection in individuals aged $\geq 65$ years has been reported [18]. This study suggested VVL to be cost-effective in Japanese adults aged $\geq 65$ years. However, VVL 


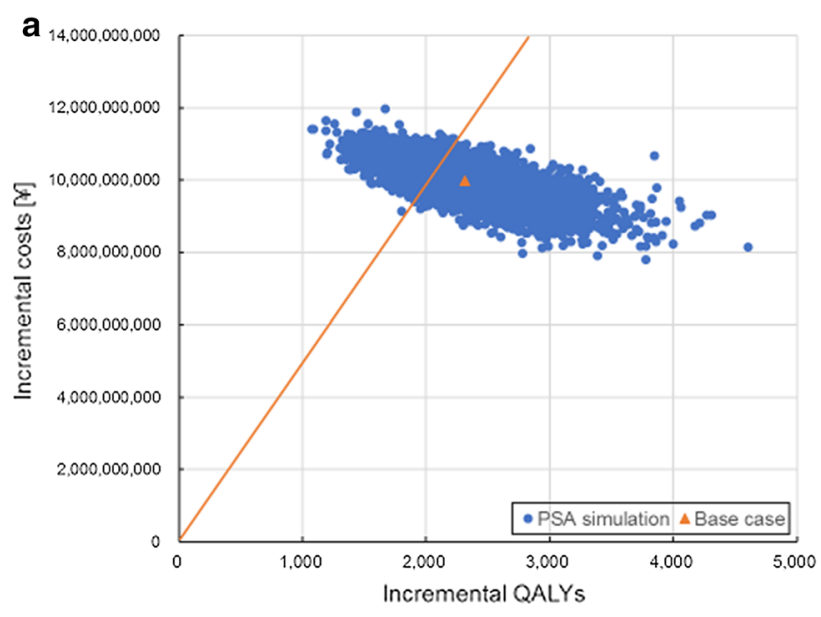

Fig. 3 Probabilistic sensitivity analysis results of 5000 Monte-Carlo simulations for Japanese adults aged $\geq 65$ years by analytical perspective. a Payer's perspective;

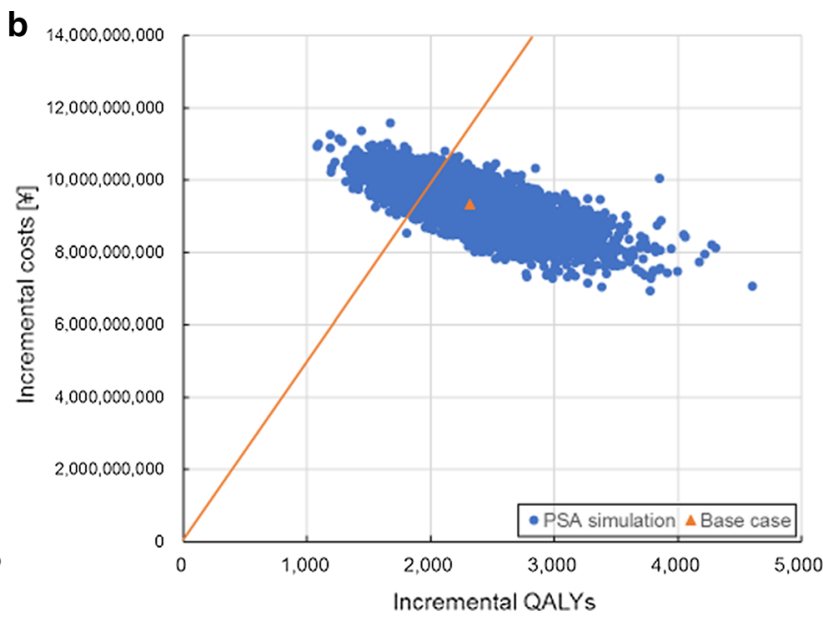

b societal perspective. PSA probabilistic sensitivity analysis, QALY quality-adjusted life year
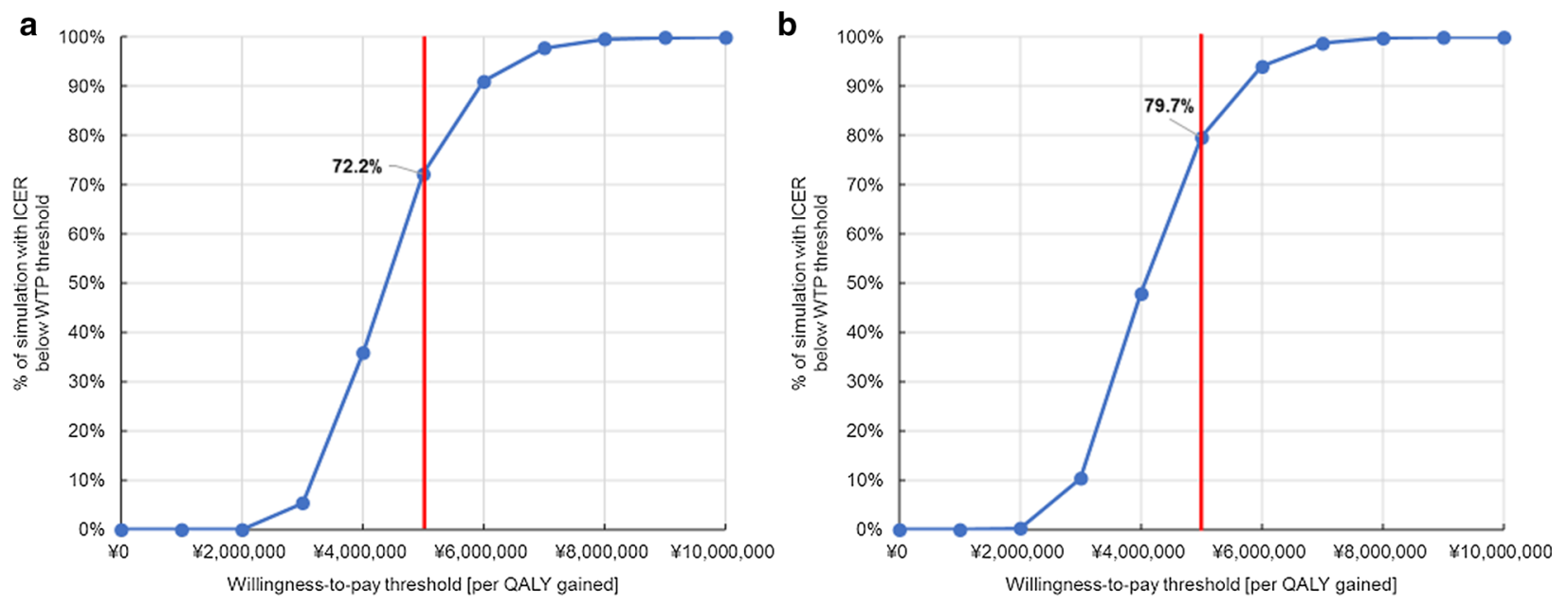

Fig. 4 Cost-effectiveness acceptability curve for Japanese adults aged $\geq 65$ years by analytical perspective. a Payer's perspective; b societal perspective. QALY quality-adjusted life year, WTP willingness to pay

is not included in the publicly funded immunization programme.

DSA suggested that the cost-effectiveness of RZV vs. no vaccination was most sensitive to assumptions regarding the waning of VE, especially for two-dose RZV in individuals aged $\geq$ 70 years. Other parameters impacting the ICER included the proportion of patients with $\mathrm{HZ}$ developing $\mathrm{PHN}, \mathrm{HZ}$ incidence, vaccine price and QALY loss for HZ with PHN. These parameters were similar to those identified in cost-effectiveness studies of ZVL vaccination [37, 38].

Waning rates, to which the ICER proved most sensitive, were estimated based on efficacy data observed in the ZOE-50 and ZOE-70 trials with the caveat of a short follow-up period of just under 4 years [32]. In a phase IIIb open, long-term extension study in 70 individuals 
having received two RZV doses as part of the ZOE trials, humoral immune response was evaluated up to 9 years post vaccination. This study showed that the initial increase in VZVspecific immune markers declined over the first 48 months after vaccination. However, cellmediated and humoral response plateaued after 4 years after vaccination to a level at least threefold above the pre-vaccination level and remained stable throughout year 9 [39]. No suspected case of $\mathrm{HZ}$ was reported during this extension study. These preliminary data suggest that RZV waning may remain stable after 4 years from vaccination up to at least 9 years after vaccination. The ICER was also sensitive to the proportion of people developing PHN following an episode of HZ. The base case probability of developing PHN (19.7\%) was taken from the same data source as HZ incidence [7]. In another Japanese prospective cohort study, a PHN proportion of $9.2 \%$ was reported, approximately $50 \%$ lower than the base-case value [25]. Therefore, in one-way DSA, the age-specific PHN proportion was reduced by $50 \%$, which represents the lower bound of values reported in cost-effectiveness analyses of herpes zoster vaccination [38, 40]. The resulting ICER increased by almost $50 \%$. In a systematic review, the risk of developing PHN was reported to vary from $5 \%$ to $>30 \%$ and was highly dependent on study design, age distribution and definition of PHN [5]. Varying HZ incidence affected RZV cost-effectiveness as well as the public health impact of RZV vaccination [19]. Epidemiological trends suggest an increase in HZ incidence over time [5,9]. In the Miyazaki study, which prospectively followed Japanese individuals of all ages over a time period of 20 years, the incidence of HZ in 2017 was 1.68 times higher than that in 1996 [27]. A White Paper by the Japanese Government on the ageing population estimated that the number of Japanese adults aged $\geq 65$ years increases for at least 20 years from now and reaches $38.1 \%$ by 2060 [41]. In the absence of an effective $\mathrm{HZ}$ prevention strategy, this would translate into an increase in health care costs associated with $\mathrm{HZ}$ and its complications. Even though variation of some parameters resulted in ICERs above the WTP of $¥ 5,000,000$, all ICERs would remain acceptable when using an alternative WTP of $¥ 6,350,000$ to $¥ 6,750,000$ per QALY gained as proposed by Ohkusa et al. [42].

One of the strengths of our model is the use of recently published Japanese epidemiological, cost and utility data $[7,10,11]$. Although there is considerable uncertainty around different parameters, such as VE in the real-world setting and over time as well as coverage and compliance, results were relatively robust under DSA and PSA.

The model has several limitations mostly related to the lack of real-world data and uncertainty around specific parameters to inform the model. Data from extended followup studies are needed to refine estimates of waning and RZV effectiveness in clinical practice. It should be noted that varying VE of RZV had little impact on cost-effectiveness within the range of parameters analyzed. In addition, there is no real-life data regarding second dose compliance for RZV in Japan. In the base-case analysis, a second dose compliance rate of $95 \%$ was assumed, based on clinical trial data $[30,31]$. Compliance rates $\geq 95 \%$ for multipledose paediatric vaccines were reported in the Japanese setting. Even though these observations are not generalizable to other age groups, these results suggest that high compliance rates are achievable in Japan. Setting the second dose compliance rate to $70 \%$, as for the US and German setting, had little impact on the ICER, although the number of $\mathrm{HZ}$ cases avoided would be $15 \%$ lower [19]. Finally, a review of epidemiological studies suggested that $>30 \%$ of patients with PHN experienced persistent pain for $>1$ year [5]. In our model, the impact of PHN on utility and costs was only counted during one annual cycle. If the model allowed for PHN to last $>1$ year the resulting ICER would decrease. In the future, coverage and compliance data from national surveillance studies as well as real-life effectiveness data need to be incorporated into the model to provide a more accurate estimate of RZV costeffectiveness.

Overall, our model showed that the RZV vaccination strategy against $\mathrm{HZ}$ is cost-effective compared with no vaccination in Japanese 
adults $\geq 65$ years and that these results were stable under a wide range of parameters tested.

\section{CONCLUSIONS}

Recombinant zoster vaccine is a new HZ-specific vaccine that has recently been licensed in Japan for the prevention of $\mathrm{HZ}$ in individuals $\geq 50$. The current study showed that RZV would be cost-effective in Japanese adults aged $\geq 65$ years compared with no vaccination. RZV was costeffective under a wide range of alternative parameters and assumptions explored.

The summary slide presents a summary of the context, outcomes and impact of this study for healthcare providers.

\section{ACKNOWLEDGEMENTS}

Funding. GlaxoSmithKline Biologicals SA was the funding source and was involved in all study activities and overall data management (collection, analysis and interpretation) of this study (GSK identifier HO-16-17837). GlaxoSmithKline Biologicals SA also funded all costs associated with the development and the publishing of the present manuscript. All authors had full access to all of the data in this study and take complete responsibility for the integrity of the data and accuracy of the data analysis.

Medical Writing, Editorial and Other Assistance. The authors thank Katsiaryna Holl (GSK Japan, at the time of the study) and Lijoy Varghese (GSK R\&D-Asia-Pacific and North Asia) for their inputs in the public health impact manuscript as author. The authors would also like to thank Giulia Povellato (GSKMedical Affairs Zoster) for her critical review of the manuscript. Katrin Spiegel provided writing assistance on behalf of GSK. The authors would like to thank Business \& Decision Life Sciences platform for editorial assistance and publication coordination on behalf of GSK. Matthieu Depuydt coordinated publication development and provided editorial support.
Authorship. All named authors meet the International Committee of Medical Journal Editors (ICMJE) criteria for authorship for this article, take responsibility for the integrity of the work as a whole and have given their approval for this version to be published.

Disclosures. Makoto Shiragami reports personal fees from the GSK group of companies Daisuke Watanabe and reports personal fees from the GSK group of companies. Akiko Mizukami is an employee of the GSK group of companies. Toshihiko Kaise is an employee of the GSK group of companies. Desmond Curran is an employee of the GSK group of companies. Desiree Van Oorschot is an employee of the GSK group of companies. Benjamin Bracke is an employee of the GSK group of companies. Toshihiko Kaise holds shares in the GSK group of companies. Desmond Curran holds shares in the GSK group of companies. Akiko Mizukami received funding from Japan Vaccine Co., Ltd. (a 50/50 joint venture of GSK/Daiichi Sankyo Co., Ltd.) for the conduct of the study. Toshihiko Kaise received funding from Japan Vaccine Co., Ltd. (a 50/50 joint venture of GSK/Daiichi Sankyo Co., Ltd.) for the conduct of the study.

Compliance with Ethics Guidelines. This article is based on previously conducted studies and does not contain any studies with human participants or animals performed by any of the authors.

Data Availability. The data sets generated during and/or analyzed during the current study are available from the corresponding author on reasonable request. If any request for data sharing comes, the requester should be directed to the website https://www. clinicalstudydatarequest.com, which is a secured portal through which data can be made available.

Trademark Statement. Shingrix is a trademark of the GSK group of companies. Zostavax is a trademark from Merck Sharp \& Dohme Corp. 
Open Access. This article is distributed under the terms of the Creative Commons Attribution-NonCommercial 4.0 International License (http://creativecommons.org/licenses/ by-nc/4.0/), which permits any noncommercial use, distribution, and reproduction in any medium, provided you give appropriate credit to the original author(s) and the source, provide a link to the Creative Commons license, and indicate if changes were made.

\section{REFERENCES}

1. Gershon AA, Gershon MD, Breuer J, Levin MJ, Oaklander AL, Griffiths PD. Advances in the understanding of the pathogenesis and epidemiology of herpes zoster. J Clin Virol. 2010;48(Suppl 1):S2-7.

2. Gershon AA, Breuer J, Cohen JI, Cohrs RJ, Gershon $\mathrm{MD}$, Gilden D, et al. Varicella zoster virus infection. Nat Rev Dis Primers. 2015;1:15016.

3. Erskine N, Tran H, Levin L, Ulbricht C, Fingeroth J, Kiefe C, et al. A systematic review and meta-analysis on herpes zoster and the risk of cardiac and cerebrovascular events. PLoS One. 2017;12(7):e0181565.

4. Johnson RW, Alvarez-Pasquin MJ, Bijl M, Franco E, Gaillat J, Clara JG, et al. Herpes zoster epidemiology, management, and disease and economic burden in Europe: a multidisciplinary perspective. Ther Adv Vaccin. 2015;3(4):109-20.

5. Kawai K, Gebremeskel BG, Acosta CJ. Systematic review of incidence and complications of herpes zoster: towards a global perspective. BMJ Open. 2014;4(6):e004833.

6. Taya K, Sato H, Oishi K, Yamada S, Saijo M. Seroprevalence of varicella zoster virus antibody: from the National Epidemiological Surveillance of Vaccine-Preventable Diseases in 2014-2017. Infect Agents Surveill Rep (IASR). 2018;39(8):133-5. https://www.niid.go.jp/niid/ja/allarticles/surveillan ce/2433-iasr/related-articles/related-articles-462/ 8231-462r03.html. Accessed Dec 2018.

7. Takao Y, Miyazaki Y, Okeda M, Onishi F, Yano S, Gomi Y, et al. Incidences of herpes zoster and postherpetic neuralgia in japanese adults aged 50 years and older from a community-based prospective cohort study: the SHEZ study. J Epidemiol. 2015;25(10):617-25.
8. Friesen KJ, Chateau D, Falk J, Alessi-Severini S, Bugden S. Cost of shingles: population based burden of disease analysis of herpes zoster and postherpetic neuralgia. BMC Infect Dis. 2017;17(1):69.

9. Varghese L, Standaert B, Olivieri A, Curran D. The temporal impact of aging on the burden of herpes zoster. BMC Geriatr. 2017;17(1):30.

10. Mizukami A, Sato K, Adachi K, Matthews S, Holl K, Matsuki T, et al. Impact of herpes zoster and postherpetic neuralgia on health-related quality of life in Japanese adults aged 60 years or older: results from a prospective, observational cohort study. Clin Drug Investig. 2018;38(1):29-37.

11. Nakamura H, Mizukami A, Adachi K, Matthews S, Holl K, Asano K, et al. Economic burden of herpes zoster and post-herpetic neuralgia in adults 60 years of age or older: results from a prospective, physician practice-based cohort study in Kushiro, Japan. Drugs Real World Outcomes. 2017;4(4):187-98.

12. Gater A, Abetz-Webb L, Carroll S, Mannan A, Serpell M, Johnson R. Burden of herpes zoster in the UK: findings from the zoster quality of life (ZQOL) study. BMC Infect Dis. 2014;14:402.

13. Chen N, Li Q, Yang J, Zhou M, Zhou D, He L. Antiviral treatment for preventing postherpetic neuralgia. Cochrane Database Syst Rev. 2014;2:CD 006866.

14. Chlibek R, Pauksens K, Rombo L, van Rijckevorsel G, Richardus JH, Plassmann G, et al. Long-term immunogenicity and safety of an investigational herpes zoster subunit vaccine in older adults. Vaccine. 2016;34(6):863-8.

15. ACIP. Advisory Committee on Immunization Practices. https://www.cdc.gov/shingles/vaccination. html2017. Accessed Dec 2018.

16. NACI. (National Advisory Committee on Immunization). Updated Recommendations on the Use of Herpes Zoster Vaccines; 2018. https://www. canada.ca/en/services/health/publications/healthyliving/updated-recommendations-use-herpes-zostervaccines.html2018. Accessed Dec 2018.

17. STIKO. Standing Committee on Vaccination. Vaccination recommendations by STIKO; $2019 \mathrm{https}$ /// edoc.rki.de/bitstream/handle/176904/5878.2/50_ 2018_Artikel.pdf?sequence=7\&isAllowed=y. Accessed Feb 2019.

18. Hoshi SL, Kondo M, Okubo I. Cost-effectiveness of varicella vaccine against herpes zoster and postherpetic neuralgia for elderly in Japan. Vaccine. 2017;35(24):3264-71. 
19. Watanabe D, Mizukami A, Holl K, Curran D, Van Oorschot D, Varghese L, et al. The potential public health impact of herpes zoster vaccination of people aged $\geq 50$ years in Japan: results of a Markov model analysis. Dermatol Ther (Heidelb). 2018;8(2): 269-84.

20. Van Oorschot D, Anastassopoulou A, Poulsen Nautrup B, Varghese L, von Krempelhuber A, Neine $M$, et al. Cost-effectiveness of the recombinant zoster vaccine in the German population aged $\geq 60$ years old. Hum Vaccin Immunother. 2019;15(1): 34-44.

21. Curran D, Patterson B, Varghese L, Van Oorschot D, Buck P, Carrico J, et al. Cost-effectiveness of an adjuvanted recombinant zoster vaccine in older adults in the United States. Vaccine. 2018;36(33): 5037-45.

22. Shiroiwa T, Fukuda T, Ikeda S, Takura T, Moriwaki K. Development of an official guideline for the economic evaluation of drugs/medical devices in Japan. Value Health. 2017;20(3):372-8.

23. Ikeda S. Policy application of health technology assessment: economic evaluation of vaccination. https://mhlw-grants.niph.go.jp/niph/search/NIDD00. do?resrchNum=201617005A. Accessed Dec 2018.

24. e-STAT. The portal site of Official Statistics in Japan. https://www.e-stat.go.jp/SG1/estat/eStatTopPortal. do2018. Accessed Dec 2018.

25. Sato K, Adachi K, Nakamura H, Asano K, Watanabe A, Adachi R, et al. Burden of herpes zoster and postherpetic neuralgia in Japanese adults 60 years of age or older: results from an observational, prospective, physician practice-based cohort study. J Dermatol. 2017;44(4):414-22.

26. Toyama N, Shiraki K, Society of the Miyazaki Prefecture D. Epidemiology of herpes zoster and its relationship to varicella in Japan: a 10-year survey of 48,388 herpes zoster cases in Miyazaki prefecture. J Med Virol. 2009;81(12):2053-8.

27. Toyama N. Large-scale epidemiological study of herpes zoster in Miyazaki Prefecture, 1997-2017, an update. Infect Agents Surveill Rep (IASR). 2018;39(8):139-141 https://www.niid.go.jp/niid/ ja/allarticles/surveillance/2433-iasr/related-articles/ related-articles-462/8235-462r07.html. Accessed Dec 2018.

28. Imafuku S, Nakayama J, Higa K, Furue M, Takahara M, Katayama I, et al. One-year follow-up of zosterassociated pain in 764 immunocompetent patients with acute herpes zoster treated with famciclovir (FAMILIAR study). J Eur Acad Dermatol Venereol. 2014;28(12):1716-22.
29. Yawn BP, Wollan PC, Kurland MJ, St Sauver JL, Saddier P. Herpes zoster recurrences more frequent than previously reported. Mayo Clin Proc. 2011;86(2):88-93.

30. Lal H, Cunningham AL, Godeaux O, Chlibek R, Diez-Domingo J, Hwang SJ, et al. Efficacy of an adjuvanted herpes zoster subunit vaccine in older adults. N Engl J Med. 2015;372(22):2087-96.

31. Cunningham AL, Lal $H$, Kovac M, Chlibek $R$, Hwang SJ, Diez-Domingo J, et al. Efficacy of the herpes zoster subunit vaccine in adults 70 years of age or older. N Engl J Med. 2016;375(11):1019-32.

32. Curran D, Van Oorschot D, Varghese L, Oostvogels L, Mrkvan T, Colindres R, et al. Assessment of the potential public health impact of Herpes Zoster vaccination in Germany. Hum Vaccin Immunother. 2017;13(10):2213-21.

33. MHLW (Ministry of Health, Labour and Welfare). MHLW vaccination information. http://www. mhlw.go.jp/topics/bcg/other/5.html. Accessed Dec 2018.

34. Honda M, Murata T, Ebata N, Fujii K, Ogawa S. Treatment patterns of postherpetic neuralgia patients before and after the launch of pregabalin and its effect on medical costs: analysis of Japanese claims data provided by Japan Medical Data Center. J Dermatol. 2017;44(7):767-73.

35. MHLW. (Ministry of Health, Labour and Welfare). Revision of Medical payment system in 2016. https://www.mhlw.go.jp/stf/seisakunitsuite/bunya/ 0000106421.html. Accessed Dec 2018.

36. Shiroiwa T, Sung YK, Fukuda T, Lang HC, Bae SC, Tsutani K. International survey on willingness-topay (WTP) for one additional QALY gained: what is the threshold of cost effectiveness? Health Econ. 2010;19(4):422-37.

37. Kawai K, Preaud E, Baron-Papillon F, Largeron N, Acosta CJ. Cost-effectiveness of vaccination against herpes zoster and postherpetic neuralgia: a critical review. Vaccine. 2014;32(15):1645-53.

38. de Boer PT, Wilschut JC, Postma MJ. Cost-effectiveness of vaccination against herpes zoster. Hum Vaccin Immunother. 2014;10(7):2048-61.

39. Schwarz TF, Volpe S, Catteau G, Chlibek R, David $\mathrm{MP}$, Richardus JH, et al. Persistence of immune response to an adjuvanted varicella-zoster virus subunit vaccine for up to year nine in older adults. Hum Vaccin Immunother. 2018;14(6):1370-7.

40. van Hoek AJ, Gay N, Melegaro A, Opstelten W, Edmunds WJ. Estimating the cost-effectiveness of 
vaccination against herpes zoster in England and Wales. Vaccine. 2009;27(9):1454-67.

41. Cabinet Office. White paper on ageing society. Government of Japan. https://www8.cao.go.jp/ kourei/whitepaper/w-2018/zenbun/30pdf_index. html. Accessed Dec 2018.
42. Ohkusa Y, Sugawara T. Research for willingness to pay for one QALY gain. Iryo To Shakai. 2006;16(2):157-65.

43. Le P, Rothberg MB. Cost-effectiveness of herpes zoster vaccine for persons aged 50 years. Ann Intern Med. 2015;163(7):489-97. 